\title{
Show-Room Mannequins
}

\section{TerRy MalanchuK}

Terry Malanchuk (melanoxylon@shaw.ca) has been a keen photographer since the age of six when he got his first Kodak Brownie Holiday Flash camera. He maintains that his style and sense of proportion have not fundamentally changed since then. His impossible dream was to own a Polaroid camera and this he achieved by age 14. Although the Polaroid was expensive, he used it for the next four years until it was stolen. He was introduced to 'real photography'(chemicals, darkrooms, etc.) at the University of Alberta. He worked here as a photographer for the Gateway newspaper and the University of Alberta Yearbook for a couple of years before attending the Northern Alberta Institute for Technology. Though photography then came to play a secondary role to a passion for motorcycling and full-time work as a motorcycle mechanic, he nonetheless produced more than 10,000 negatives in the 1970s. Most of the prints were given away to friends as soon as they were dry; all the negatives were destroyed on one day in a deliberate and malicious act designed to cause the photographer great pain. Terry returned to the artistic use of the camera only on November 17, 1999.

\section{Artist's Statement}

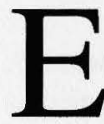
ach dictionary has its own definition of art and artist. Webster's New World defines an artist as "a person who does anything very well, with a feeling for form, effect, etc." An artisan is "a skilled workman or craftsman." I claim both titles, having worked in both fields, although 'artist,' to be valid, must be conferred by one's peers (other artists) whereas an 'artisan's work' can be measured by empirical means.

Yet there is overlap between the two. I have seen 'snapshots' hidden away where no one ever sees them, a few of which are undoubtedly works of art. I have also seen a few photographs in respected galleries that I wouldn't pull out of the garbage.

Styles in architecture, clothing, the use of color, etc., change

torquere: Journal of the Canadian Lesbian and Gay Studies Association /

Revue de la Société canadienne des études lesbiennes et gaies

Vol. 3 (2001) () CLGSA / SCELG 


\section{2 / Malanchuk}

radically over a relatively short period of time - say, a few decades. Next time you are at a Value Village or Goodwill store, look at some books describing, for instance, clothing and architectural styles of the late 1960 s to the late 1970s. The criminal use of color (purple, orange, avocado, harvest gold), smoked glass, patterned gilded mirrors, furniture that appears to have been created using only an axe - and all of this in the same room!

So was it mass hysteria?

Drive around Edmonton and notice the architecture and use of color. There are tens of thousands of new dwellings having as the main architectural feature a triple garage and an entryway with a 17 ceiling, curved staircase, and gaudy chandelier. All in 'architecturally controlled' subdivisions. All in the same 'inoffensive' colors. How will these stand the test of time?

I would often drive past a shop that sold show-room mannequins (I refuse to call them 'dummies'). One night I spotted a pair of Lucite women's 'gams' in the window. I was then totally hooked and the wonderful staff gave me the run of the place. I was fascinated to find out that the mannequins are made from molding casts that were made from 'real' people. Once 'perfect' bodies from 40 - or four thousand - years ago are still valid today. (Of course, garish repainting can make them valid only to a certain time or place.) So is beauty essentially timeless? Is beauty innate? Is beauty ever 'architecturally controlled'?

Portrait photos of circa turn of the century were always serious, painstaking, and made to impress one's peers, friends, and - perhaps - enemies. I remember when my cousin and I were 13 years old we put our 25 cents (for 4 different poses) into a mechanized photo booth. The first photo was serious, the other three were making gaudy faces, smirks, and waving our tongues around. (Mooning had not been invented then.) When we showed these pictures to my grandfather he literally glowed at seeing the first exposure. Seconds later he was beetroot red and frothing at the mouth.

When I do the printing I just stand back and see what happens. I then choose the themes and motifs that speak to me and toss in a bit of metaphor and hyperbole. Some prints almost print themselves; others may be cajoled. My 'style' is based on a belief in an inherent sense of proportion; this can be used in a grand manner, a mediocre manner, or in parody. Rules are made to be broken. I love angles, 
usually acute but sometimes oblique. Squares are to be avoided, but again: rules are made to be broken.

The most import technique is having a vision of the desired result. Second must be to do one's own printing. Lastly, expensive or esoteric cameras are not required. One of my favorite cameras I bought from a Goodwill store for 99 cents.

My advice is to shoot lots of film and try to make each exposure the best you can. Ten mediocre photos of something that attracts you are nothing compared to the one that sums it all up. Also, some negatives are so easy to print that it seems there is nothing to it. Then there is the negative that takes two days and 50 sheets of paper to get it Just Right. Near my enlarger is the quote: "We choose to do these things not because they are easy ..."

The photographer thanks Normand and Value Store Fixtures.

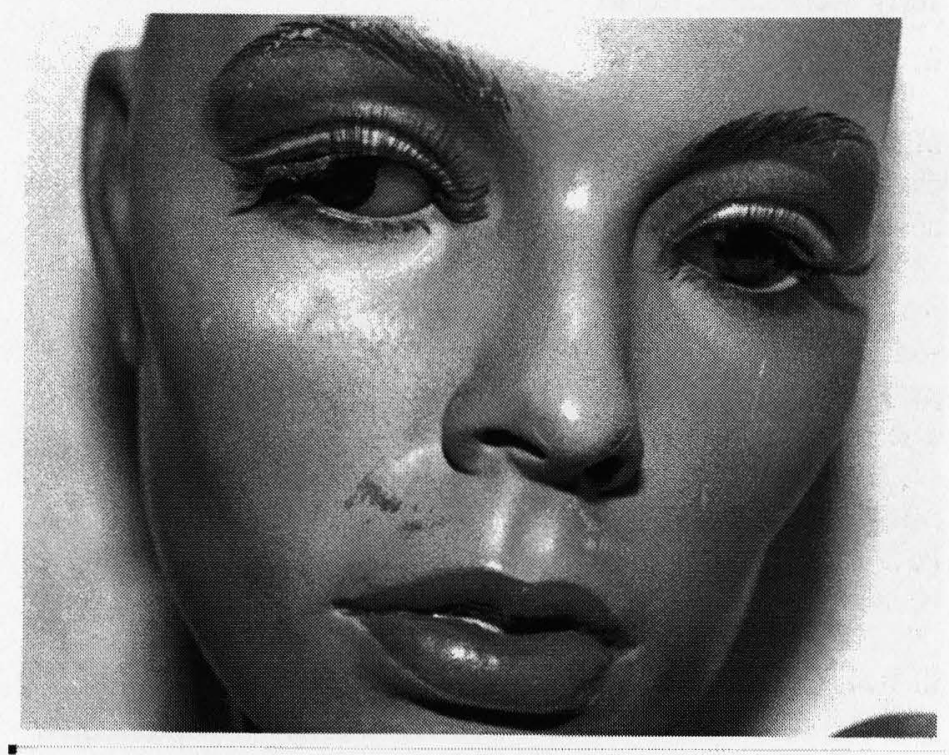

Terry Malanchuk, Mommie on Morphine. 
134 / Malanchuk

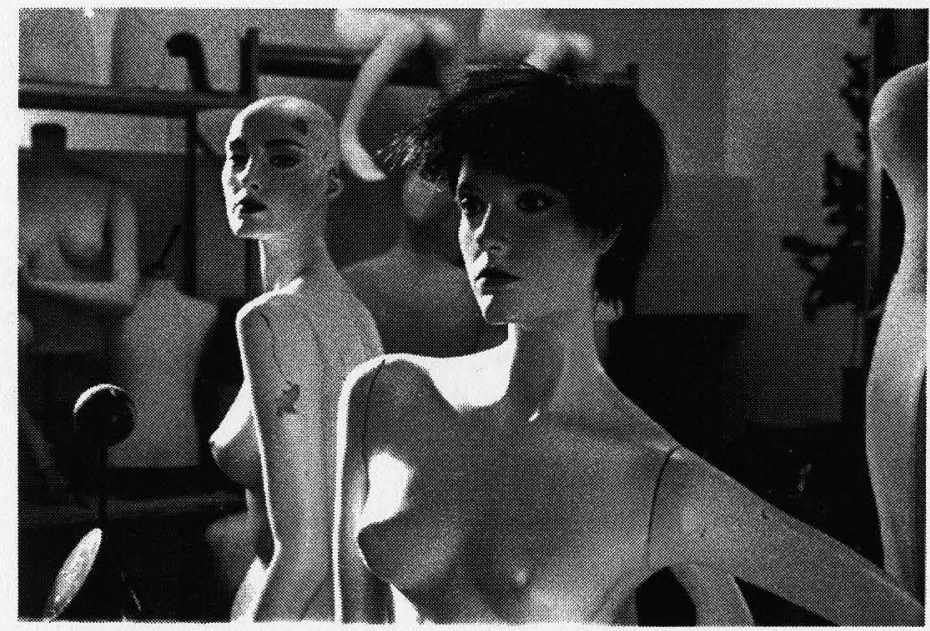

Terry Malanchuk, Vogue.

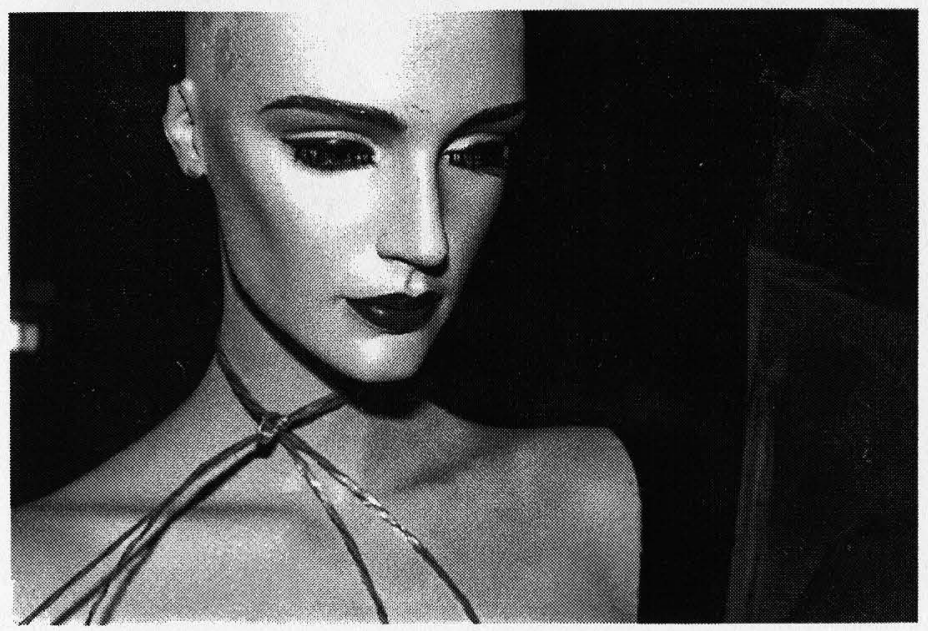

Terry Malanchuk, Drag Queen. 
Mannequins / 135

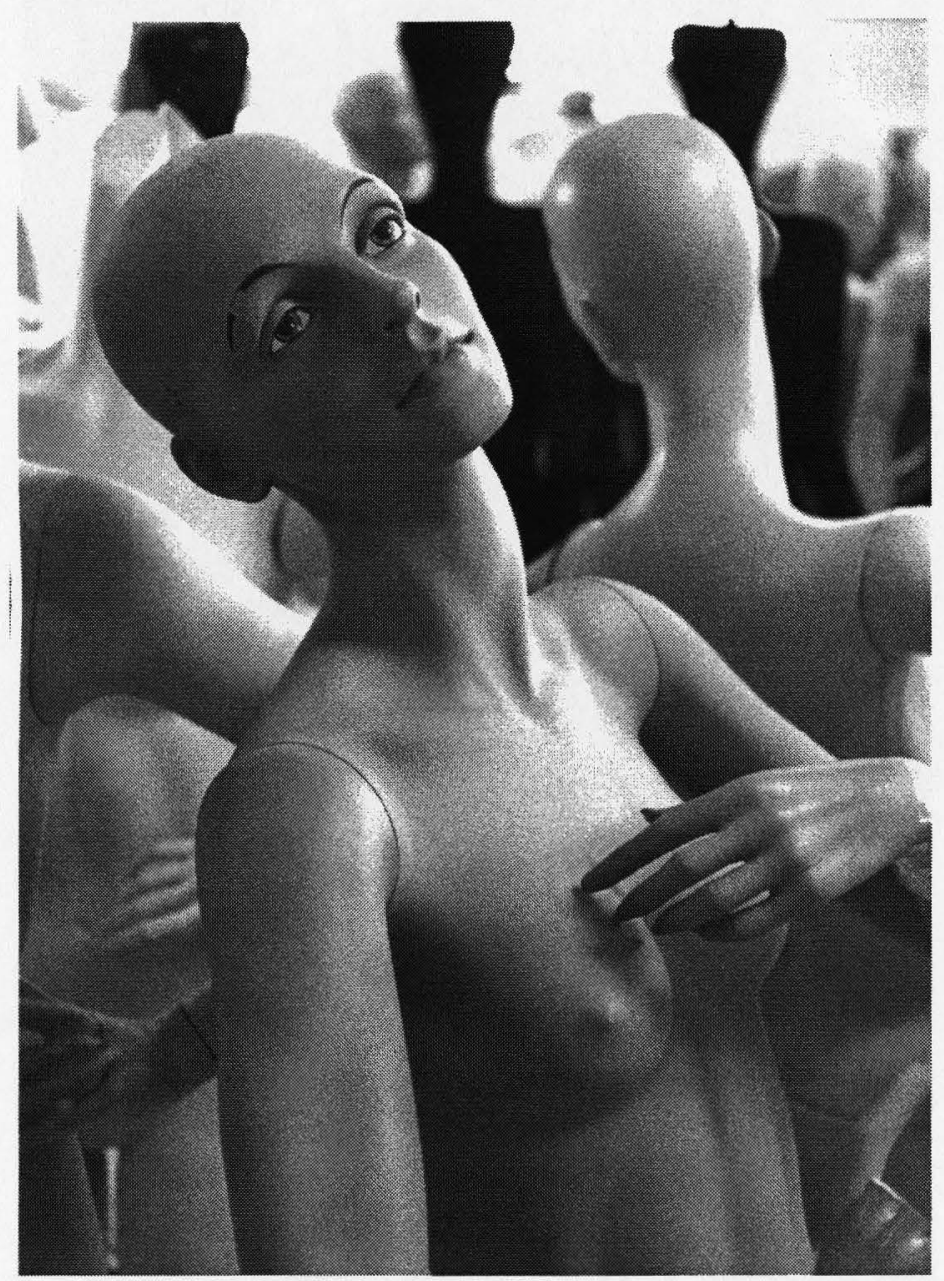

Terry Malanchuk, Serene Sacrifice. 
136 / Malanchuk

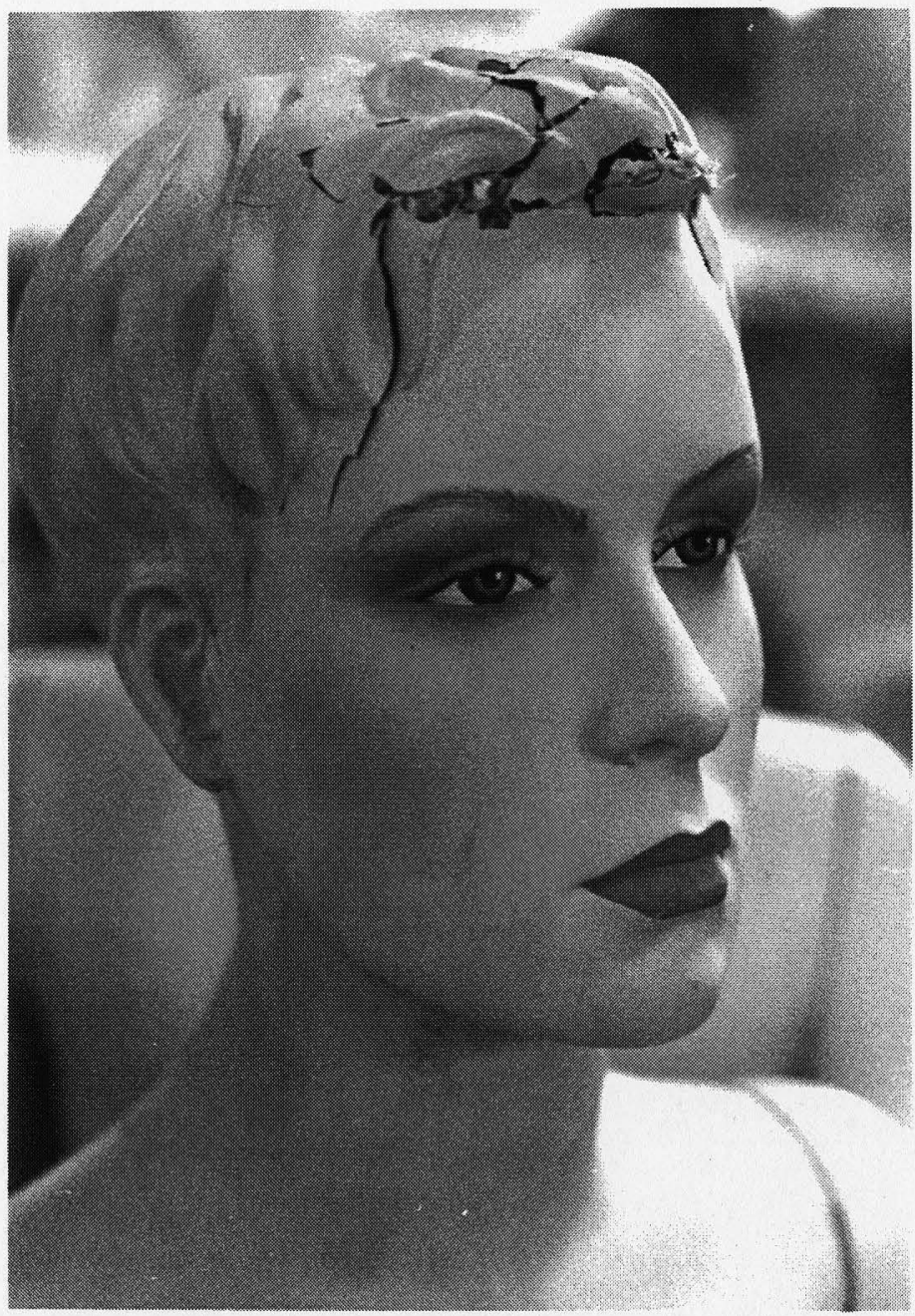

Terry Malanchuk, Cracked 1950/Rita Hayworth. 